\title{
Prognostic Factors in Mexican Patients with Patchy and Other Types of Alopecia Areata
}

\author{
Erick Alejandro Jiménez-Herrera Zamira Rios-Garza \\ María Luisa Peralta-Pedrero Fermin Jurado-Santa Cruz \\ Martha Alejandra Morales-Sánchez \\ Research and Education Unit, Centro Dermatológico “Dr. Ladislao de la Pascua, Mexico City, Mexico
}

\section{Keywords}

Alopecia areata $\cdot$ Adherence $\cdot$ Hair loss

\begin{abstract}
Introduction: Some clinical features have been associated with the progression and remission of alopecia areata (AA). We aim to determine possible prognostic factors in Mexican patients with AA. Methods: This prospective study of a 1-year follow-up included Mexican patients with a clinical diagnosis of AA. We evaluated disease activity with the SALT score at the first visit and 1-year follow-up; progression, no progression, and remission were defined according to score changes. We used multiple linear regression model to detect factors associated with progression and remission. Results: One hundred and four patients concluded the study. Ninety-seven patients (93.3\%) had patchy AA. Fifteen patients showed disease progression and 89 no progression, of which 35 pa-
\end{abstract}

karger@karger.com www.karger.com/sad

Karger $\stackrel{2}{\circ}$ tients had remission. Body hair involvement was related to disease progression and adherence to treatment with disease remission and progression. Conclusions: Body hair involvement is related to poor prognosis. Adherence to treatment is a modifiable prognostic factor associated with the course of AA in Mexican patients.

(c) 2020 S. Karger AG, Basel

\section{Introduction}

Alopecia areata (AA) is an autoimmune disease and the second most common cause of non-scarring alopecia, behind androgenetic alopecia [1]. The prevalence of AA in general population is $0.2 \%$ and affects approximately $2 \%$ of Mexican population [2]. The main pathogenesis features are loss of "follicle immune privilege" and activation of CD8+ T cells against follicle autoanti- 
Table 1. Sociodemographic and clinical features of patients with AA at the initial evaluation and loss of patients in the follow-up

\begin{tabular}{|c|c|c|c|}
\hline & $\begin{array}{l}\text { Initial evaluation } \\
(n=120)\end{array}$ & $\begin{array}{l}\text { Final evaluation } \\
(n=104)\end{array}$ & $p$ value \\
\hline \multicolumn{4}{|l|}{ Sociodemographic features } \\
\hline \multicolumn{4}{|l|}{ Sex, $n(\%)$} \\
\hline Female & $70(58.3)$ & $44(42.3)$ & \multirow[t]{2}{*}{0.71} \\
\hline Male & $50(41.7)$ & $60(57.7)$ & \\
\hline Age, years (median [range]) & $25.5(75)$ & $25.5(75)$ & 0.75 \\
\hline \multicolumn{4}{|l|}{ Clinical features } \\
\hline \multicolumn{4}{|l|}{ Type of AA, $n(\%)$} \\
\hline Patchy & $112(93.3)$ & $97(93.3)$ & \multirow[t]{4}{*}{0.98} \\
\hline Ophiasis & $2(1.7)$ & $2(1.9)$ & \\
\hline Totalis & $4(3.3)$ & $4(3.8)$ & \\
\hline Universalis & $2(1.7)$ & $1(1)$ & \\
\hline Disease duration, years (median [range]) & $1(27)$ & $1(27)$ & 0.98 \\
\hline Age at disease onset, years (mean $\pm \mathrm{SD})$ & $24.8 \pm 15.4$ & $24.8 \pm 15.8$ & 0.98 \\
\hline Initial SALT score (median [range]) & $6.5(100)$ & $7.0(100)$ & 0.27 \\
\hline \multicolumn{4}{|l|}{ Body score, $n(\%)$} \\
\hline B0 & $98(81.7)$ & $86(82.7)$ & \multirow[t]{3}{*}{0.44} \\
\hline B1 & $18(15)$ & $15(14.4)$ & \\
\hline B2 & $4(3.3)$ & $3(2.9)$ & \\
\hline \multicolumn{4}{|l|}{ Nail score, $n(\%)$} \\
\hline N0 & $104(86.7)$ & $90(86.5)$ & \multirow[t]{3}{*}{0.95} \\
\hline N1 & $12(10)$ & $11(10.6)$ & \\
\hline N1a & $4(3.3)$ & $3(2.9)$ & \\
\hline \multicolumn{4}{|l|}{ Episodes, $n(\%)$} \\
\hline 1 episode & $82(68.3)$ & $73(70.1)$ & \multirow[t]{4}{*}{0.71} \\
\hline 2 episodes & $28(22.3)$ & $21(20.2)$ & \\
\hline 3 episodes & $5(4.1)$ & $5(4.8)$ & \\
\hline$\geq 4$ episodes & $5(4.1)$ & $5(4.8)$ & \\
\hline Ungueal involvement, $n(\%)$ & $20(16.7)$ & $18(17.3)$ & 0.51 \\
\hline Body hair involvement, $n(\%)$ & $24(20)$ & $20(19.2)$ & 0.59 \\
\hline
\end{tabular}

gens [3]. Disease severity is assessed by the Severity Alopecia Tool (SALT) score, which evaluates hair loss extension in the scalp and body. AA is associated with genetic factors and other autoimmune diseases: systemic lupus erythematosus (SLE), vitiligo, and psoriasis [4].

The course of AA is unpredictable. Eighty percent of patients with AA and low hair extension could present spontaneous remission. Some clinical features reported to increase disease severity are chronic disease activity, extensive hair loss, concomitant autoimmune disease, atopic dermatitis, and ungueal involvement [1]. However, factors that influence course and prognosis in patients under treatment are controversial. Studies of prognostic factors in Mexican patients with AA under treatment have not been published. Therefore, we aim to determine possible prognostic factors in Mexican patients with AA.

Prognostic Factors in Patchy Alopecia Areata

\section{Materials and Methods}

\section{Patient Selection}

This prospective study included patients with a clinical diagnosis of AA of any age and gender, attending to "Dr. Ladislao de la Pascua" Dermatology Center from February 2017 to December 2017. Then, the patients were followed up for 1 year. Patients must have disease activity, defined as the presence of at least 2 of the following criteria: positive pull test with gentile traction of 40-60 hair follicles from 3 different parts of the plaque and loss of $>10$ hair follicles, puffy consistency of the plaque, and a trichoscopy with "exclamation hair follicle sign," hair follicle dystrophy, and black dots. Exclusion criteria were loss to follow-up and not agreeing to participate.

\section{Sociodemographic Features}

In the first visit, patients answered a structured interview evaluating sociodemographic features and family and personal history of $\mathrm{AA}$, vitiligo, atopic dermatitis, psoriasis, systemic lupus erythematosus, thyroid disease, irritable bowel disease, rheumatoid arthritis, di- 
Table 2. Clinical features of the progression and no progression groups $(N=104)$

\begin{tabular}{|c|c|c|c|}
\hline & $\begin{array}{l}\text { Progression } \\
(n=15)\end{array}$ & $\begin{array}{l}\text { No progression } \\
(n=89)\end{array}$ & $p$ value \\
\hline \multicolumn{4}{|l|}{ Type of AA, $n(\%)$} \\
\hline Patchy & $12(80)$ & $85(95.5)$ & 0.03 \\
\hline Ophiasis & $2(13.3)$ & $0(0)$ & \\
\hline Totalis & $1(6.7)$ & $3(3.4)$ & \\
\hline Universalis & $0(0)$ & $1(1.1)$ & \\
\hline Age at disease onset, years (mean $\pm \mathrm{SD})$ & $16.4 \pm 13.2$ & $26.4 \pm 15.8$ & 0.027 \\
\hline Disease duration, years (median [range]) & $2(23)$ & $1(27)$ & 0.29 \\
\hline Body hair involvement, $n(\%)$ & $8(53.3)$ & $12(13.4)$ & $<0.01$ \\
\hline Ungueal involvement, $n(\%)$ & $5(33.3)$ & $13(14.6)$ & 0.086 \\
\hline \multicolumn{4}{|l|}{ Episodes, $n(\%)$} \\
\hline 1 episode & $11(73.3)$ & $62(69.7)$ & 0.363 \\
\hline 2 episodes & $3(20)$ & $18(20.2)$ & \\
\hline 3 episodes & $0(0)$ & $5(5.6)$ & \\
\hline$\geq 4$ episodes & $1(6.7)$ & $4(4.5)$ & \\
\hline \multicolumn{4}{|l|}{ Treatment, $n(\%)$} \\
\hline Topical steroids & $9(69.2)$ & $66(77.6)$ & 0.507 \\
\hline Intralesional steroids & $7(53.8)$ & $22(25.6)$ & 0.081 \\
\hline Systemic steroids & $5(38.5)$ & $7(8.1)$ & 0.002 \\
\hline Topical psoralens & $5(38.5)$ & $15(17.4)$ & 0.080 \\
\hline Phototherapy & $1(7.7)$ & $3(3.5)$ & 0.475 \\
\hline Retinoids & $0(0)$ & $3(3.5)$ & 0.496 \\
\hline \multicolumn{4}{|l|}{ Adherence to treatment, $n(\%)$} \\
\hline $100 \%$ & $5(33.3)$ & $42(47.1)$ & 0.43 \\
\hline $90 \%$ & $4(26.6)$ & $34(38.2)$ & \\
\hline $89-60 \%$ & $4(26.6)$ & $12(13.4)$ & \\
\hline $59-30 \%$ & $1(6.6)$ & $0(0)$ & \\
\hline $29-10 \%$ & $0(0)$ & $1(1.1)$ & \\
\hline$<10 \%$ & $1(6.6)$ & $0(0)$ & \\
\hline
\end{tabular}

abetes mellitus (DM), systemic arterial hypertension, obesity, cardiovascular disease, toxicomania, and allergies. In the second visit at 1-year follow up, we investigated a new diagnosis of vitiligo, atopic dermatitis, asthma, allergic rhinitis, urticaria, autoimmune disease, psoriasis, thyroid disease, DM, hypertension, obesity, and dyslipidemia. If positive, laboratories and treatments were recorded.

\section{Clinical Features of $A A$}

Age at disease onset, disease duration, number of activity episodes, hair loss pattern, treatments, and ungueal and body hair involvement were registered. Iconographic control was taken according to AA Investigational Assessment Guidelines Criteria [5]. One dermatologist evaluated disease severity with the SALT score at first and 1 year later visits. Patients were divided into disease progression and no progression groups according to the SALT score changes. We defined disease progression as an increase in the 1-year SALT score compared to initial SALT score and no progression a 1-year SALT score with decrease or without changes compared to initial SALT score. Patients with a 1 -year SALT score of 0 were defined as remission. Adherence to treatment was evaluated by a structured questionnaire, and we defined good adherence to treatment a score of $90-100 \%$ and bad adherence $<90 \%$

\section{Statistical Analysis}

The distribution of variables was assessed using the Kolmogorov-Smirnov test. We reported abnormally distributed variables with median and ranges, normally distributed quantitative variables with mean and $\mathrm{SD}$, and qualitative variables with percentages. We used the Mann Whitney $U$ test to compare abnormally distributed variables and the $\chi^{2}$ test to correlate disease progression, no progression, and remission groups. Variables with statistical significance were included in a multiple linear regression model. Finally, we assessed variables with statistical significance with a proportional risk model using the Cox regression model and graphing with the Kaplan-Meier curves. We considered $p<0.05$ as statistically significant. We analyzed data with SPSS version 25 .

\section{Results}

One hundred and twenty patients were included in the study, and 16 patients were unable to return to the Dermatology Center (13.3\% loss of patients). Sociodemographic and clinical features are shown in Table 1. 
Table 3. Sociodemographic and clinical features of the progression and remission groups $(N=50)$

\begin{tabular}{|c|c|c|c|}
\hline & $\begin{array}{l}\text { Progression } \\
(n=15)\end{array}$ & $\begin{array}{l}\text { Remission } \\
(n=35)\end{array}$ & $p$ value \\
\hline \multicolumn{4}{|l|}{ Sociodemographic features } \\
\hline \multicolumn{4}{|l|}{ Sex, $n(\%)$} \\
\hline Female & $12(80)$ & $15(42.9)$ & 0.12 \\
\hline Male & $3(20)$ & $20(57.1)$ & \\
\hline Age, years (median [range]) & $24(44)$ & $35(41)$ & 0.06 \\
\hline \multicolumn{4}{|l|}{ Family history, $n(\%)$} \\
\hline AA & $3(20)$ & $10(28.6)$ & 0.53 \\
\hline Atopic dermatitis, asthma, allergic rhinitis, and urticaria & $1(6.7)$ & $0(0)$ & 0.33 \\
\hline Diabetes mellitus & $8(53.3)$ & $0(0)$ & 0.53 \\
\hline Systemic arterial hypertension & $7(46.7)$ & $0(0)$ & 0.76 \\
\hline Thyroid disease & $2(13.3)$ & $0(0)$ & 0.93 \\
\hline Autoimmune diseases ${ }^{\mathrm{a}}$ & $4(26.6)$ & $3(8.5)$ & 0.61 \\
\hline \multicolumn{4}{|l|}{ Personal history, $n(\%)$} \\
\hline Vitiligo & $0(0)$ & $3(8.6)$ & 0.24 \\
\hline Atopic dermatitis, asthma, allergic rhinitis, and urticaria & $3(20)$ & $3(8.6)$ & 0.26 \\
\hline Thyroid disease & $1(6.7)$ & $0(0)$ & 0.12 \\
\hline Diabetes mellitus & $0(0)$ & $0(0)$ & 1 \\
\hline Systemic arterial hypertension & $0(0)$ & $0(0)$ & 1 \\
\hline Dyslipidemia & $1(6.7)$ & $4(11.4)$ & 0.61 \\
\hline Autoimmune diseases ${ }^{\mathrm{a}}$ & $1(6.7)$ & $0(0)$ & 0.12 \\
\hline \multicolumn{4}{|l|}{ Smoking, $n(\%)$} \\
\hline Active & $3(20)$ & $9(25.7)$ & 0.67 \\
\hline Inactive & $2(13.3)$ & $6(17.1)$ & 0.73 \\
\hline Alcoholism & $5(33.3)$ & $16(45.7)$ & 0.42 \\
\hline \multicolumn{4}{|l|}{ Clinical features } \\
\hline Disease duration, years (median [range]) & $2(23)$ & $1(27)$ & 0.29 \\
\hline Age at disease onset, years (mean $\pm S D)$ & $16.4 \pm 13.2$ & $28.1 \pm 13.8$ & 0.01 \\
\hline Initial SALT score (median [range]) & $18(91)$ & $4(15)$ & $<0.01$ \\
\hline Body score, $n(\%)$ & & & $<0.01$ \\
\hline B0 & $7(46.73)$ & $33(94.3)$ & 0.25 \\
\hline B1 & $8(53.3)$ & $2(5.7)$ & \\
\hline B2 & $0(0)$ & $0(0)$ & \\
\hline \multicolumn{4}{|l|}{ Nail score, $n(\%)$} \\
\hline No & $12(80)$ & $32(91.4)$ & \\
\hline N1 & $3(20)$ & $3(8.6)$ & \\
\hline N1a & $0(0)$ & $0(0)$ & \\
\hline Final SALT score (median [range]) & $20.5(96)$ & $0(0)$ & $<0.01$ \\
\hline Body score, $n(\%)$ & & & $<0.01$ \\
\hline B0 & $7(46.73)$ & $33(94.3)$ & 0.01 \\
\hline B1 & $8(53.3)$ & $2(5.7)$ & \\
\hline $\mathrm{B} 2$ & $0(0)$ & $0(0)$ & \\
\hline \multicolumn{4}{|l|}{ Nail score, $n(\%)$} \\
\hline N0 & $10(66.7)$ & $32(91.4)$ & \\
\hline N1 & $5(33.3)$ & $3(8.6)$ & \\
\hline N1a & $0(0)$ & $0(0)$ & \\
\hline \multicolumn{4}{|l|}{ Episodes, $n(\%)$} \\
\hline 1 episode & $11(73.3)$ & $27(43.3)$ & 0.80 \\
\hline 2 episodes & $3(20)$ & $5(15.4)$ & \\
\hline 3 episodes & $0(0)$ & $2(14.3)$ & \\
\hline$\geq 4$ episodes & $1(6.7)$ & $1(2.9)$ & \\
\hline \multicolumn{4}{|l|}{ Type of AA, $n(\%)$} \\
\hline Patchy & $12(80)$ & $35(100)$ & $<0.01$ \\
\hline Ophiasis & $2(13.3)$ & $0(0)$ & \\
\hline Totalis & $1(6.7)$ & $0(0)$ & \\
\hline
\end{tabular}


Table 3 (continued)

\begin{tabular}{|c|c|c|c|}
\hline & $\begin{array}{l}\text { Progression } \\
(n=15)\end{array}$ & $\begin{array}{l}\text { Remission } \\
(n=35)\end{array}$ & $p$ value \\
\hline Universalis & $0(0)$ & $0(0)$ & \\
\hline Ungueal involvement, $n(\%)$ & $5(33.3)$ & $3(8.6)$ & 0.03 \\
\hline Body hair involvement, $n(\%)$ & $8(53.3)$ & $2(5.7)$ & $<0.01$ \\
\hline \multicolumn{4}{|l|}{ Treatment, $n(\%)$} \\
\hline Topical steroid & $9(69.2)$ & $24(72.7)$ & 0.81 \\
\hline Intralesional steroid & $7(53.8)$ & $6(17.6)$ & 0.03 \\
\hline Systemic steroid & $5(38.5)$ & $2(5.9)$ & $<0.01$ \\
\hline Topical psoralen & $5(38.5)$ & $4(11.8)$ & 0.04 \\
\hline Topical retinoid & $1(7.7)$ & $1(2.9)$ & 0.53 \\
\hline Phototherapy & $0(0)$ & $0(0)$ & 0.1 \\
\hline \multicolumn{4}{|l|}{ Adherence to treatment, $n(\%)$} \\
\hline $100 \%$ & $5(33.3)$ & $21(60)$ & 0.02 \\
\hline $90 \%$ & $4(26.6)$ & $10(28.5)$ & \\
\hline $89-60 \%$ & $4(26.6)$ & $3(8.5)$ & \\
\hline $59-30 \%$ & $1(6.6)$ & $0(0)$ & \\
\hline $29-10 \%$ & $0(0)$ & $1(2.8)$ & \\
\hline$<10 \%$ & $1(6.6)$ & $0(0)$ & \\
\hline
\end{tabular}

a Psoriasis, systemic lupus erythematosus, rheumatoid arthritis, bullous diseases, and vasculitis.

\section{Clinical Features of Disease}

Most of the patients had patchy AA (93.3\%) and low initial SALT score (median 7 points, range 100). The mean age at disease onset was $24.8 \pm 15.8$ years. Patients with patchy AA showed a mean age at disease onset of $25.55 \pm 15.5$ years and median disease evolution of 3.15 (range 1-27), 69\% one episode, and 78\% good adherence to treatment. These clinical features were not statistically different compared to other types of AA.

Body hair involvement was found in 15 patients with patchy AA (15.5\%), 1 patient with totalis AA (25\%), 1 patient with ophiasis AA (50\%), and 1 patient with universalis AA (100\%) without statistically significant differences $(p=0.08)$.

Fifteen patients had disease progression and 89 patients no progression. Eighty percent of patients with disease progression had patchy AA, median disease duration of 2 years (range 23), mean age at disease onset of $16.4 \pm$ 13.2 years, $53.3 \%$ had body hair involvement, and $59.9 \%$ good adherence to treatment. Clinical and treatment features of these groups are shown in Table 2.

Thirty-five patients from no progression group had disease remission. All patients presented with patchy AA, median disease duration of 1 year (range 27), mean age at disease onset of $28.1 \pm 13.8$ years, and low prevalence of ungueal and body hair involvement (8.6 and 5.7\%, re- spectively). Clinical and treatment features of the remission group are shown in Table 3.

In both groups, the main causes of bad adherence to treatment were no time and forgetting to apply the treatment and irritation with topical medications. Patients with worse adherence to treatment in both groups were under treatment with topical steroids, minoxidil, and psoralens.

\section{Factors Associated with Disease Course}

Sociodemographic features were not associated with disease progression or remission. Comparisons of clinical features between disease progression and no progression groups showed that the earliest age at disease onset and body hair involvement were more frequent in patients with progression ( $p=0.02$ and $p<0.01$, respectively). Other clinical and treatment features did not show statistically significant differences (Table 2).

Subanalysis of progression and remission groups showed significant differences with age (median 24 vs. 35 years, $p=$ 0.06 ), age at disease onset (median 8.5 vs. 31 years, $p=0.01$ ), ungueal involvement ( 33.3 vs. $8.6 \%, p=0.03)$, body hair involvement (53.3 vs. $5.7 \%, p<0.01$ ), and treatment with intralesional steroid ( 53.8 vs. $17.6 \%, p=0.03$ ), systemic corticotherapy ( 38.5 vs. $5.9 \%, p<0.01$ ), and topical psoralen ( 38.5 vs. $11.8 \%, p=0.04)$. Good adherence to treatment was 
Table 4. Multiple linear regression model for factors associated with disease progression

\begin{tabular}{|c|c|c|c|c|c|c|}
\hline Variable & $N$ & $\%$ & $\chi^{2}, p$ value & $B$ & $95 \% \mathrm{CI}$ & $p$ value \\
\hline \multicolumn{7}{|c|}{ Body hair involvement } \\
\hline Present & $8 / 15$ & 53.3 & & & & \\
\hline Absent & $7 / 15$ & 46.7 & $<0.01$ & 0.798 & 0.42 to 1.17 & $<0.01$ \\
\hline \multicolumn{7}{|c|}{ Body score (SALT score) } \\
\hline B0 & $7 / 15$ & 46.7 & & & & \\
\hline $\mathrm{B} 1$ & $8 / 15$ & 53.3 & & & & \\
\hline B2 & $0 / 15$ & 0.0 & $<0.01$ & 0.468 & 0.16 to 0.78 & 0.03 \\
\hline \multicolumn{7}{|c|}{ Adherence to treatment } \\
\hline $100 \%$ & $5 / 15$ & 33.3 & & & & \\
\hline $90 \%$ & $4 / 15$ & 26.6 & & & & \\
\hline $89-60 \%$ & $4 / 15$ & 26.6 & & & & \\
\hline $59-30 \%$ & $1 / 15$ & 6.6 & & & & \\
\hline $29-10 \%$ & $0 / 15$ & 0.0 & & & & \\
\hline$<10 \%$ & $1 / 15$ & 6.6 & $<0.01$ & -0.88 & -0.15 to -0.021 & 0.01 \\
\hline
\end{tabular}

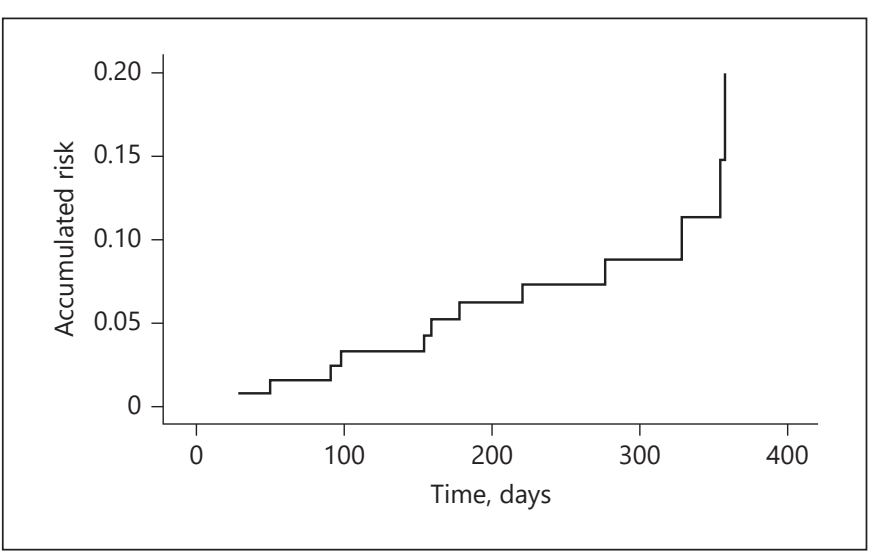

Fig. 1. Body hair involvement in AA patients with disease progression with Cox regression.

more prevalent in the remission group than in the progression group ( 85.3 vs. $59.9 \%, p=0.02$ ) (Table 3 ).

Factors with statistical differences between progression and no progression groups were included in a multiple linear regression model. Body hair involvement according to body score of SALT score and adherence to treatment were associated with disease progression (Table 4). The Cox regression analysis showed that body hair involvement was related to disease progression during the follow up ( $p=0.04$; OR 1.26, 95\% CI: 1.04-12.0) (Fig. 1, 2).

Finally, we included statistical relevant factors from the subanalysis of patients with disease remission in the multiple linear regression model. Body hair involvement showed a negative association with disease remission (Table 5).

Prognostic Factors in Patchy Alopecia Areata

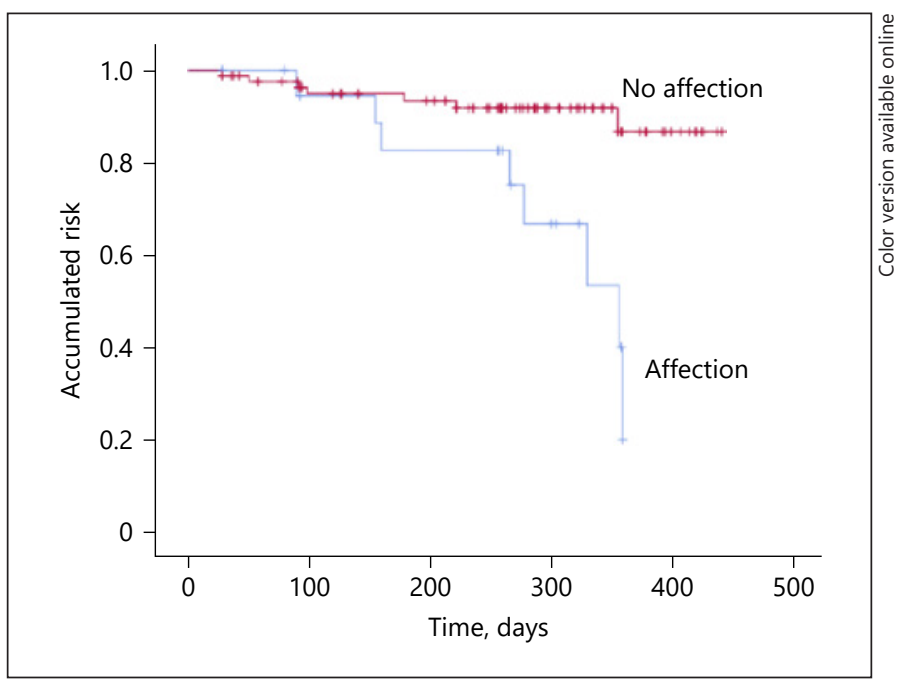

Fig. 2. Kaplan-Meier curves for body hair involvement.

\section{Discussion}

AA is an autoimmune disease that causes significant psychological and cosmetic impact on patients. The frequency in Mexican dermatologic consult is 1\% [6]. AA has a heritable basis, and specific genes have been associated with disease severity and concomitant diseases. We evaluated the family history of patients with AA including inflammatory and autoimmune disease, which did not show any relevance on disease course during follow-up. Patients with disease progression had a higher prevalence of positive family history of atopic dermatitis, DM, sys- 
Table 5. Multiple linear regression model for factors associated with disease remission

\begin{tabular}{lrrrrrr}
\hline Variable & $N$ & $\%$ & $\chi^{2}, p$ value & $B$ & $95 \%$ CI & $p$ value \\
\hline $\begin{array}{l}\text { Body hair involvement } \\
\quad \begin{array}{l}\text { Present } \\
\text { Absent }\end{array}\end{array}$ & $2 / 35$ & 5.7 & & & & \\
\hline
\end{tabular}

temic arterial hypertension, and thyroid disease compared to the remission group, which were not statistically significant.

The relevance of a positive family history of AA in disease course is controversial. Studies report that $10-51.6 \%$ of patients with AA have a personal history of a first-degree relative with $\mathrm{AA}$, which is related to disease onset before 30 years of age [7]. In the present study, 10-24\% of patients had a family history of AA, which did not affect the disease course. The small size of the progression and remission groups and a low prevalence of this family history could explain our results.

Several factors have been reported to determine disease severity in AA. Previous studies have found that low hair loss during activity episodes is related to a spontaneous remission, with $80 \%$ of patients with complete regrowth in 1 year. Therefore, ophiasis or totalis AA show a high prevalence of progression [8]. In our study, we did not find any relation between progression and type of AA in the multiple linear regression model. Similar results have been reported in a recent study [9].

We found that disease onset at an early age and AA types with extensive hair loss were more prevalent in patients with progression than in no progression group, with similar results reported previously $[10,11]$. Lyakhovitsky et al. [10] found that patients with disease onset at an early age had a higher prevalence of disease severity. However, some authors have not found these associations [9] and remain controversial.

In our study, body hair involvement was the most important prognostic factor associated with disease progression. This clinical feature has been related to extensive hair loss, progression, relapses, and a recalcitrant disease [1]. Vañó-Galván et al. [12] described clinical features associated with bad prognosis in 80 patients with universalis AA and 52 patients with totalis AA. They found that universalis AA and family history of AA were the most important factors associated with a bad prognosis (OR 4.77, 95\% CI: 0.6-31, and OR 3.73, 95\% CI: 0.7-42.8, respectively). These results have been reported by other studies [13]. In the present study, body hair involvement was present in all types of AA. We proposed that this clinical feature could be an independent prognostic factor associated with progression in Mexican patients with AA. To our concern, studies describing the molecular mechanisms and clinical relevance of body hair involvement in patients with AA have not been published. This prognostic factor could be considered in the therapeutic approach and future research of patients with recalcitrant AA in Mexico and other countries.

Treatment of AA has been under active research in the last decade, and numerous novel therapeutic options have been published, especially for recalcitrant AA. However, corticotherapy is still one of the most useful treatments for AA. Our patients with disease progression had more prevalence of systemic corticotherapy in comparison with no progression patients, probably related to extensive hair loss and no response to other treatment modalities. We found that corticotherapy and adherence to treatment were not statistically related to disease progression. However, when we considered disease remission from no progression group, we found a higher prevalence of good adherence to treatment in the remission group compared to the progression group. Good adherence to treatment showed a negative statistical correlation with disease progression in multiple linear regression model. Patient orientation about clinical and treatment features of AA could improve adherence to treatment and prognosis [14]. Besides, we have reported that depression, anxiety, and suicide affect the quality of life and prognosis of patients with AA [15]. We propose that a good orientation, treatment adaptability according to patients' occupations, and listening to their requirements in dermatologic consultation could increase the probability to reach remission.

\section{Conclusions}

Body hair involvement is related to poor prognosis. Adherence to treatment is a modifiable prognostic factor associated with the course of AA in Mexican patients. 


\section{Acknowledgements}

The authors thank Germán Guerrero-Oliva, MD, and Quetzalli Chirino-Castillo, MD, for their work in recruiting participants.

\section{Statement of Ethics}

This study was approved by local ethics committee according to the Helsinki Declaration. Informed consent was obtained from all patients.

\section{Conflict of Interest Statement}

The authors have no conflicts of interest to declare.

\section{Funding Sources}

No funding sources were employed in this study.

\section{Author Contributions}

E.A.J.-H. conceived the idea of the manuscript and contributed to the analysis and interpretation of data and drafting the manuscript. Z.R.-G. contributed to include patients in the study, interview patients, and acquisition of data for statistical analysis. M.L.P.-P. contributed to methodological design, analysis of data, and final approval of the version to be published. F.J.-S.C. developed the theoretical formalisms and conception of the work and revised and approved the final version of the work. M.A.M.-S. was responsible for study design, implementation, and enrollment of participants; analyzed and interpreted the data; reviewed the first draft; and approved the final manuscript.

\section{References}

1 Pratt CH, King LE Jr, Messenger AG, Christiano AM, Sundberg JP. Alopecia areata. Nat Rev Dis Primers. 2017;3(3):17011-3.

2 Jabbari A, Petukhova L, Cabral RM, Clynes R, Christiano AM. Genetic basis of alopecia areata: a roadmap for translational research. Dermatol Clin. 2013;31(1):109-17.

3 Islam N, Leung PS, Huntley AC, Gershwin ME. The autoimmune basis of alopecia areata: a comprehensive review, Autoimmun Rev. 2015;14(2):81-9.

4 Fricke, ACV, Miteva, M. Epidemiology and burden of alopecia areata: a systematic review. Clin Cosmet Investig Dermatol. 2015;8:397403.

5 Olsen EA, Hordinsky MK, Price VH, Roberts JL, Shapiro J, Canfield D, et al. Alopecia areata investigational assessment guidelines: part II. National Alopecia Areata Foundation. J Am Acad Dermatol. 2004;51(3):440-7.

6 Martínez-Suárez, H. Alopecia areata. Dermatol Rev Mex. 2015;59:395-405.
7 Rocha J, Ventura F, Vieira AP, Pinheiro AR, Fernandes S, Brito C. [Alopecia areata: a retrospective study of the paediatric dermatology department (2000-2008)]. Acta Med Port. 2011;24(2):207-14.

8 Selmi C, Leung PS, Sherr DH, Diaz M, Nyland JF, Monestier M, et al. Mechanisms of environmental influence on human autoimmunity: a National Institute of Environmental Health Sciences expert panel workshop. J Autoimmun. 2012;39(4):272-84.

9 Uchiyama M, Egusa C, Hobo A, Irisawa R, Yamazaki M, Tsuboi R. Multivariate analysis of prognostic factors in patients with rapidly progressive alopecia areata. J Am Acad Dermatol. 2012;67(6):1163-73.

10 Lyakhovitsky A, Aronovich A, Gilboa S, Baum S, Barzilai A. Alopecia areata: a longterm follow-up study of 104 patients. J Eur Acad Dermatol Venereol. 2019;33(8):1602-9.

11 Sharma VK, Dawn G, Kumar B. Profile of alopecia areata in Northern India. Int J Dermatol. 1996;35(1):22-7.
12 Vañó-Galván S, Fernández-Crehuet $\mathrm{P}$, Grimalt R, García-Hernández MJ, RodriguesBarata R, Arias-Santiago S, et al. Alopecia areata totalis and universalis: a multicenter review of 132 patients in Spain. J Eur Acad Dermatol Venereol. 2017;31(3):550-6.

13 Jang YH, Hong NS, Moon SY, Eun DH, Lee WK, Chi SG, et al. Long-term prognosis of alopecia totalis and alopecia universalis: a longitudinal study with more than 10 years of follow-up: better than reported. Dermatology. 2017;233(2-3):250-6.

14 Brown MT, Bussell J, Dutta S, Davis K, Strong S, Mathew S. Medication adherence: truth and consequences. Am J Med Sci. 2016; 351(4):387-99.

15 Vélez-Muñiz Rd C, Peralta-Pedrero ML, Jurado-Santa Cruz F, Morales-Sánchez MA. Psychological profile and quality of life of patients with alopecia areata. Skin Appendage Disord. 2019;5(5):293-298. 